\title{
Radio Frequency Ablation of Osteoid Osteoma in Common and Technically Challenging Locations in Pediatric Population
}

Shaileshkumar Garge ${ }^{1}$ Shyamkumar N. Keshava² Vinu Moses² George Koshy² Munawwar Ahmed² Suraj Mammen² Vrisha Madhuri²

\footnotetext{
${ }^{1}$ Department of Radiology, Christian Medical College, Vellore, Tamil Nadu, India

${ }^{2}$ Department of Paediatric Orthopedics, Christian Medical College, Vellore, Tamil Nadu, India
}

Asian J Oncol 2017;3:35-38.

\section{Retraction Notice}

Concerning the article "Radio frequency ablation of osteoid osteoma in common and technically challenging locations in pediatric population" published in Asian Journal of Oncology, Volume 3, Number 1, 2017 (DOI: 10.4103/ASJO.ASJO_54_16),
Address for correspondence Shailesh Kumar Garge, Department of Radiology, Christian Medical College, Vellore 632 004, Tamil Nadu, India (e-mail: drshaileshgarge@gmail.com).

it has been brought to the publisher's attention that the article has already been published in Indian Journal of Radiology and Imaging, Volume 27, Number 1, 2017 and therefore the author has requested to withdraw the article.

For this reason, the article has been retracted in accordance with COPE guidelines. 